\title{
A COMPLEXITY UNDERPINNING FOR DOMESTIC CLIMATE MITIGATION POLICY IN SOUTH AFRICA
}

\author{
E. TYLER ${ }^{1} \&$ B. COHEN ${ }^{2}$ \\ ${ }^{1}$ Energy Research Centre, University of Cape Town, South Africa. \\ ${ }^{2}$ Department of Chemical Engineering, University of Cape Town, South Africa.
}

\begin{abstract}
This paper explores the proposition that a complex systems approach may provide a useful conceptual underpinning for understanding and developing domestic climate mitigation policy in a developing country, using South Africa as a case study.

Framing South African climate mitigation policy as a system contextualised by, and radically open to, the broader South African social, technological, economic, environmental, physical and political system highlights the properties and mechanisms of complex social systems, thereby re-ordering policy priorities and leverage points. But further, a complexity frame or paradigm is a radical departure from its modernist predecessor. The complexity principles that underpin this frame suggest different entry points, foci and practices as being appropriate for the South African climate mitigation policy community.

Keywords: climate mitigation, complex dynamic systems, complexity thinking, developing country, policy, South Africa.
\end{abstract}

\section{INTRODUCTION}

This paper introduces a complexity framing to domestic climate change mitigation policy in South Africa (hereafter, 'SA climate mitigation policy'), and argues that this appears sufficiently appropriate and productive so as to warrant further enquiry. The quest to seek out such an alternative framing was borne out of the authors' frustration as practitioners in the SA climate mitigation policy community with the lack of a coherent underpinning to relevant research and practice in a developing country context, and with increasing problems with implicit assumptions utilised by the climate mitigation community of practice Tyler [1].

\section{THE POINT OF OBSERVATION}

The authors are long-standing (2004) and active members of the SA climate mitigation policy community of practice, working primarily as consultants to the government, the private sector, civil society and academia. Two specific sets of fieldwork were also undertaken in 2014 by the primary author towards the exploration of a complexity view of SA climate mitigation policy. The first of these was a set of face-to-face open-ended interviews with the SA climate change mitigation and development communities of practice, focused on the Long Term Mitigation Scenario planning process (LTMS), a seminal SA climate mitigation policy initiative. The second was a series of eight-themed, facilitated, two-hour focus groups, the 'MAPS Conversations', involving SA climate mitigation researchers and development practitioners. These focus groups, which were held under the auspices of the MAPS Programme 
(www.mapsprogramme.org), proceeded as a set of discussions about the interface between the different policy areas, and similarities and differences in approaches to practice.

\section{REFRAMING THE SOUTH AFRICAN CLIMATE MITIGATION POLICY CHALLENGE AS A COMPLEX SYSTEMIC ONE}

Complexity thinking has been identified by a number of authors as an appropriate framing for climate mitigation globally, with climate mitigation policy being described as a quintessential complex systemic policy challenge [2,3] requiring system transformation Tyler [4]. This is perhaps particularly so in a development context where certain policy making characteristics and challenges in relation to the climate mitigation policy problem are prevalent Tyler [4].

\subsection{Complex systemic properties of SA domestic climate mitigation policy}

Complex systems are theorised, largely under 'restricted' complexity views Morin [5], as having particular properties. There is an extensive debate on the extent to which observed properties of natural complex systems can be applied to social systems, which have the added complexity of involving humans with their particular levels of agency, consciousness, and an ability to learn Wells [6]. Complexity authors from the social sciences believe this can be done at least in an applied sense (see for example Shine [7]), and on this basis a number of these properties are used here to map a complex view of SA climate mitigation policy.

\subsubsection{Complex system(s)-of-interest and boundaries}

Systems are an essential feature of complexity, with one definition of complexity stating that complexity theory is the theory of the multi-agent system Heylighen et al. [8]. Currently, SA climate mitigation policy is neither explicitly nor routinely considered from a systemic perspective. Rather, it has entered the SA policy environment as an international environmental issue Tyler [1], with the Department of Environment (DEA) as the policy owner focusing on regulatory emissions targeting as the primary policy objective.

From a complexity view, two 'systems of interest' Ison [2] can be identified in relation to SA climate mitigation policy. The first is the country's social, technological, economic, environmental, physical and political (SA STEEPP) Peter and Swilling [9] system itself, which will not be described further, given the scope of the paper. The second is South Africa's domestic low carbon policy system, which is both 'contextualised' by, and is 'radically open' to, the first system (these complexity principles are considered further later on). The boundary around this latter system is set to include those elements whose primary purpose is concerned with climate mitigation, including officials at all three tiers of government, companies, civil society individuals and organisations, academia, policy documents, technologies, projects and programmes.

Currently, the SA climate mitigation policy is seldom contextualised within the broader SA socio-economic context. Despite many efforts to adequately theorise climate mitigation in a development context (see for example Winkler et al. [10], Winkler et al. [11], have neither adopted a framing that places the systemic nature of the challenge as central, nor brought the body of literature that comprises complexity thinking to bear on this task. 


\subsubsection{A networked system}

Complex systems are networked systems, where interconnections between system elements are more relevant in understanding the system's self-organisation and emergent properties than any detailed understanding of the elements themselves.

SA climate mitigation policy has typically focused on mitigation interventions that can be conceptualised and accounted for within sectors, as opposed to those that span and interconnect sectoral and departmental silos. For example, 'consumption' is a powerful mitigation lever that is missed in a sectoral analysis MAPS Programme [12]. Further, there is very little interlinking of climate mitigation policy initiatives across the three tiers of government, and very little integration of climate mitigation policy into other areas of SA policy beyond the rhetorical, where words such as 'sustainable development' and 'green economy' are used to describe fringe elements of the SA STEEPP system rather than a systemic transformation Forti [13]. For example, aspects of the 'environmental chapter' of the National Development Plan are inconsistent with policy proposals in other chapters, and provincial and city spheres are scarcely mentioned in SA's National Climate Change Response White Paper (NCCRWP), apart from the requirement for them to give effect to the national level policy document Republic of South Africa [14]. Only lately have approaches that emphasise connections, such as socio-technical transitions theory Baker [15] and science and technology studies Rafey [16] provided insights into the networked nature of the mitigation policy community, emphasising the importance of aspects such as political economy, and systemic transformation.

A complex networked perspective would aim to understand the interconnections between the components of the SA climate mitigation policy system, and identify which acted as 'hubs', or highly connected components, capable of rapidly augmenting a desirable or undesirable feedback loop. These could be carefully monitored by the DEA and appropriately supported or if undesirable, contained. A focus on connections would heighten the DEA's ability to identify cross-cutting mitigation opportunities, and those aligned with other developmental policy objectives.

\subsubsection{Emergent properties}

Complexity thinking suggests that whilst complex systems are essentially unpredictable, there is a patterning to their emergent properties, an emergent ordering through change Shine [7] Wells [6].

The emergent properties of the SA domestic carbon mitigation policy and STEEPP systems, and the patterning to these, are what these systems are actually producing and sustaining. For the SA STEEEPP system this is high carbon intensity, high unemployment and high inequality. The climate mitigation policy system's emergent properties are rising absolute emissions levels, an adversarial stakeholder environment Tyler and Torres Gunfaus [17], low political and policy relevance, and disconnect from its STEEPP context. Despite much policy intention to do the opposite, both systems appear drawn to the high carbon, unequal and un-cooperative 'attractor'. A complexity view of SA climate mitigation policy would focus attention on understanding these patterns, and on how to influence them.

\subsubsection{Feedback and non-linearity}

A complex system is characterised by non-linearities and feedback, resulting in a fundamental unpredictability of how the system will respond and evolve. A complexity view thus 
suggests that analysing the current state of a complex system and using it as a basis for future projections of that system is misguided.

SA climate mitigation policy has to date focused on developing and quantifying linear emissions pathways to 2050, extrapolating from the current socio-economic structure and utilising the concept of 'Business as Usual' against which to compare the outcomes of climate policy implementation Department of Environmental Affairs [18], Scenario Building Team [19]. A preferred approach to developing climate mitigation policy would be to look to both the climate mitigation policy and the SA STEEPP system for complex features such as tipping points, thresholds and feedback loops. The SA energy sector's preference to large technology projects offers many instances of these.

\subsubsection{Structure and heterarchy}

Whilst complex systems are argued as being hierarchical in structure, this is not a 'topdown', centralised, rigid hierarchy as traditionally understood, but rather one aligned with the observed fractal nature of natural systems, where patterns are repeated at various levels. Complex systems have structure, but this structure is not fixed and has vitality as hierarchies are transformed Cilliers [20]. Peter and Swilling [9] employ the concept of heterarchy, or 'flexible hierarchies' where functions rise to authority as required, for a limited period.

SA climate mitigation policy is centrally organised by DEA, whose focus is nationally oriented and the linkages between national and other policy levels are poorly developed in the Republic of SA [14]. However, the 'nested' hierarchy of the policy system is evident in how similar arguments and discussions, viewpoints and positions are mirrored at various scales and in various contexts. An explicit recognition of this by the DEA could support learning across the system, including the adaption of national policy in response to what is emerging at the local level, and the rapid adoption of a policy breakthrough or innovation at a local level throughout either the SA STEEPP or the SA mitigation policy system. Employing the concept of heterarchy would enable the DEA to facilitate temporary leadership in response to particular opportunities.

\subsection{Complexity principles}

A perspective on complexity thinking most fully expressed in the philosophies of generalised (Morin) and critical (Cilliers) complexity emphasises the principles, or 'frame of reference' Peter and Swilling [9] which underpin a complex view, and complex systems and problems. These are ways of seeing, understanding and acting within a complex reality. A selection of these, and their mapping to the SA systems-of-interest are discussed below.

\subsubsection{Contextuality}

The complexity principle of contextuality Chu et al. [21] emphasises the integral importance of the context of any system; at its essence, the distinction between any system-of-interest and its context only exists in the eyes of the observer Ison [2]. A complex system constantly self-organises in response to this context, resulting in emergent properties of the system being uniquely contextually determined. This perspective, therefore, foregrounds 'managing for context' for any policy challenge.

SA climate mitigation policy has been strongly framed by mitigation concepts introduced by the international climate mitigation policy environment Tyler [1], where development and 
climate mitigation are viewed sequentially. Technology, finance and a focus on policy instruments to reduce emissions pre-dominate Shove [22]. The links between SA climate mitigation policy and the country's development policy priorities remain conceptualised within a highlevel 'win-win' framing of the climate-development policy challenge Scenario Building Team [19], rather than a framing that enables the deeply contextual inter-relationships to be understood, managed and mined for the opportunities they offer.

Complexity thinking, underpinned by the principle of contextuality offers such a framing. The climate-development challenge has to be worked out at sites, scales and representations throughout the SA climate mitigation policy system, in each interaction with its SA STEEPP context. Relevant contextual aspects could be anticipated to include the country's apartheid history and racial sensitivities (most climate mitigation practitioners outside of government are white, whilst most government officials are black, engendering a particular dynamic), the political economy of the energy and mining sectors, the monopolistic structure of the energy sector, the history of low energy costs and the 2008 electricity supply crisis, and the spatial legacies of apartheid pertaining to urban and infrastructural form.

Contextuality advises that actors in one system may have different roles in a contextual system, providing both opportunities and threats to a policy objective. For example, the emissions constraint of $275 \mathrm{Mt}$ of $\mathrm{CO}_{2}$, a direct derivation from numbers in the LTMS process, was incorporated directly into the energy policy because the Eskom member of the LTMS SBT 'steamrollered' National Treasury and the Department of Public Enterprise to accept the outcomes as relevant to Tyler and Torres Gunfaus [17]. Identifying these actors, and supporting and influencing them then becomes a relevant focus for climate mitigation policy.

\subsubsection{Radical openness}

Radical openness refers to a movement in one system causing unpredictable changes in related systems Chu et al. [21], driving unpredictability and instability in both systems. The current framing of SA climate mitigation policy does not consider this interplay between systems explicitly, relying instead on a far more stable and certain view of the policy challenge, relegating much of the interaction as 'uncertainty' that requires quantification and assessment, rather than exploitation. This view constrains adequate identification of and preparation for the challenges to a low carbon systemic transformation, and to the on-going influence and resilience of the high carbon emergent properties of the SA STEEPP system such as its predilection for large technology energy infrastructure projects.

It also underplays the opportunities that this interaction offers. The 'peak' identified in South Africa's Peak, Plateau and Decline trajectory (reflected in both the domestic policy's National Greenhouse Gas Benchmark Trajectory Range Republic of SA [14], the country's Copenhagen Pledge Wills [23], and incorporated into the Integrated Resource Plan of 2010) was the first time emissions were quantitatively considered in energy planning, and the emissions constraint signalled a shift in South African energy policy Morris and Martin [24].

The complexity principle of radical openness (together with that of contextuality) also allows for an understanding of the interaction between both SA systems and international climate policy system. The agreements, concepts, finance, political support and mechanisms it provides, together with the information, focus and compliance it requires have significant implications for domestic low carbon policy Tyler and Torres Gunfaus [17], and at times SA concepts and negotiating skills have influenced the international policy system. There has been little theorising of these interconnections yet. 


\subsubsection{Uncertainty, unknowability and anti-fragility}

The principles of uncertainty and unknowability are essential to generalised complexity, emphasising that every observation of the system is only that; one perspective at one particular moment in time. These principles present a radical challenge to the modernist worldview, where the 'truth' is considered knowable with sufficient knowledge, and uncertainty is an anomaly to be managed. The principle of 'antifragility' Peter and Swilling [9] holds that uncertainty and volatilities, far from being aspects to control for are actually sources of generativity and innovation. Experimentation and innovation are necessary aspects of a viable complex system.

In SA, climate mitigation policy has been oriented towards evidence-based policymaking and linear projections and analysis, emphasising data, technology and costs such as the 'wedge' approach used in the LTMS, and McKinsey's Mitigation Abatement Cost Curves used in the Mitigation Potential Analysis. The DEA's approach has been strongly influenced by its expertise in environmental regulation, evidenced by the top-down, centralised control of the 'cascading' carbon budgets and inflexibility around absolute emissions targets Tyler and Torres Gunfaus [17]. A high degree of certainty about economic structure, growth rates, technologies and the nature of the international economy is assumed going forward. The SA climate mitigation policy system also takes a limited view of innovation and experimentation, conceiving of it largely as pertaining to technology, to be encouraged by establishing a number of institutional niches and financial incentive schemes and through the 'stick' of the carbon tax.

Complexity thinking ranks numbers and regulation low in terms of effective places to intervene in a system Meadows [25], and replaces this misplaced belief in control with the principles of ethics and cultivating agility, flexibility, anticipation and responsiveness in the face of certain uncertainty. Fostering an environment and culture of experimentation in all areas of climate mitigation, from policy to governance to management to technologies to behavioural change to financing is advantageous in a complex system's view. Failure and redundancy are features of this environment, and necessary in order to support system resilience in the face of uncertainty and unpredictability. At points where the instability in the system is highest, lies the greatest momentum for tipping, and for transformation.

Scale becomes important here, as policy innovations arising from implementation in various contexts can then be replicated throughout the system. Emison [26] finds that innovation is easier at a lower 'sub-ordinate' level, perhaps akin to City level policy initiatives in the SA climate mitigation policy system. The REIPPP which has been argued as being highly successful at an international scale [24] emerged after a period of policy experimentation (a feed-in tariff was partially developed but eventually politically blocked Baker [15]. Innovations can also be translated between systems. An LTMS interviewee Tyler and Torres Gunfaus [17] speculated that the LTMS' participatory approach may have influenced the greater (than previous) inclusion of participation in the electricity planning process.

\subsubsection{Sub-optimisation}

Richardson [9] argues that stable self-organisation of complex systems requires that their component sub-systems operate non-optimally. Trade-offs at a sub-system level are, therefore, necessary.

SA climate mitigation policy remains largely driven by the desire for a 'win-win' approach to undertaking mitigation in a development context. There was a perception at the 2014 National Climate Change Response Conference that the issue of trade offs was being skirted, that these discussions are yet to happen. The LTMS implied significant losers in the shift from 
'Business as Usual' to any of the described mitigation trajectories, but did not explicitly engage with Tyler and Torres Gunfaus [17]. The extent of exemptions in the planned SA carbon tax reinforces this view. Only recently has there been any substantial analysis of the olitical economy of climate mitigation policy Baker et al. [27], Baker [15], Chandrashekeran et al. [28], Death [29], Morris and Martin [24].

The necessity of a sub-system sub-optimisation for complex system sustainability prioritises facing these trade-offs. This requires a strategic discussion and plan pertaining to a managed transformation of the centre of the SA economy at the executive level, something which does not exist in SA Morris and Martin [24].

\subsection{Specific considerations from the literature on complexity for public policy}

Complexity thinking for public policy has been described as a lens, and a way to describe and explain the policymaking world based on a particular understanding of the natural and social world Robert Geyer and Cairney [30]. A literature exists [7, 30, 31, 32, 33] which, whilst relatively new and emergent, provides a wealth of additional insights for the SA climate mitigation policy challenge.

The realm of future work, unpacking these additional insights includes:

- Exploring the implications of developing an adaptive, agile and responsive policy approach, one of managing a journey to a low carbon country as opposed to applying emissions targets;

- Considering how a system-of-systems approach to managing the climate mitigation policy problem could assist in establishing a specific focus on maintaining political support for the policy, and supporting 'emergent implementation' Dombkins [31];

- Establishing a complexity practice within the SA policymaking community;

- Recognising the importance of incorporating insights from different disciplines and communities of practice into climate mitigation policymaking work (trans-disciplinarity);

- Re-assessing how data and knowledge generation are approached, with a focus on understanding the patterning of emergent properties;

- Understanding how ethics can guide action in the face of something that is unknown.

\section{CONCLUSION}

This paper has attempted to articulate aspects of a complexity framework for SA climate mitigation policy, identifying how it could address the inadequacies of the historically dominant implicit approaches to climate mitigation policy making in a development context, and suggesting productive priorities, approaches and practices for future work. In doing so it does not dismiss the modernist reductionist techniques and the disciplines of economics and engineering that have dominated SA climate mitigation policy (and climate mitigation policy internationally) out of hand, but rather the paradigm to which they have been perhaps overly attached.

There is a significant amount of work required to fully articulate a complexity approach to policy making for the quintessentially complex policy challenge of climate mitigation policy in a development context such as SA, not to mention the challenges of making this work in a system still dominated at all levels by the modernist paradigm. But the authors trust that this paper presents a convincing argument as to why it may be a useful exercise to continue. 


\section{REFERENCES}

[1] Tyler, E., Reflecting on Climate Mitigation Policy in a Development Context: How do we do what we do? Maps Programme Issue 30, 2015.

[2] Ison, R.L., Systems Practice: How to Act in a Climate Change World, Springer-Verlag: London, 2010.

[3] Levin, K., Cashore, B., Bernstein, S. \& Auld, G., Overcoming the tragedy of super wicked problems: Constraining our future selves to ameliorate global climate change. Policy Sciences, 45(2), pp. 123-152, 2012. http://dx.doi.org/10.1007/s11077-012-9151-0

[4] Tyler, E., Complex Dynamic Systems Thinking and Domestic Climate Mitigation Policy in Developing Countries: Part 1: Theoretical Background, MAPS Programme Issue 34, 2015.

[5] Morin, E., Restricted complexity, general complexity. In Intelligence de la complexite: epitemologie et pragmatique, pp. 1-25, 2006.

[6] Wells, J., Complexity and Sustainability, Routledge: London and New York, 2006.

[7] Shine, C.T., Policymaking as complex cartography? Mapping and achieving probable futures using complex concepts and tools. In eds R. Geyer \& P. Cairney, Handbook on Complexity and Public Policy (First), Edward Elgar Publishing, 2015. http://dx.doi.org/10.4337/9781782549529.00018

[8] Heylighen, F., Cilliers, P. \& Gershenson, C., Complexity and philosophy. In Complexity, Science and Society, Radcliffe Publishing: Oxford, pp. 117-134, 2007.

[9] Peter, C. \& Swilling, M., Linking complexity and sustainability theories: Implications for modeling sustainability transitions. Sustainability (Switzerland), 6, pp. 1594-1622, 2014. http://dx.doi.org/10.3390/su6031594

[10] Winkler, H., Boyd, A., Torres Gunfaus, M. \& Raubenheimer, S., Reconsidering development by reflecting on climate change. International Environmental Agreements: Politics, Law and Economics, 15(4), pp. 369-385, 2015. http://dx.doi.org/10.1007/s10784-015-9304-7

[11] Winkler, H., Spalding-fecher, R., Mwakasonda, S. \& Davidson, O., Sustainable development policies and measure : starting from development to tackle climate change. In Building on the Kyoto Protocol: Options for Protecting the Climate, pp. 61-87, 2002.

[12] MAPS Programme, MAPS Conversations, 2014.

[13] Forti, C., Change Development Not Climate! Analysis of the sustainable development approach in South Africa in dealing with climate change and development issues, University of Amsterdam, 2013.

[14] Republic of South Africa, National Climate Change Response White Paper, p. 27, 2011.

[15] Baker, L.H., Power shifts? The Political Economy of Socio-technical Transitions in South Africa's Electricity Sector, University of East Anglia, 2012.

[16] Rafey, W.M., Visions and Models in South Africa: Balancing Energy Development with Global Climate Change, Harvard College, 2013.

[17] Tyler, E. \& Torres Gunfaus, M., LTMS Interviews, 2014.

[18] Department of Environmental Affairs, Defining South Africa's Peak, Plateau and Decline Greenhouse Gas Emission Trajectory, 2011.

[19] Scenario Building Team, Long Term Mitigation Scenarios Strategic Options for South Africa, 2007. 
[20] Cilliers, P., Complexity theory as a general framework for sustainability science. In Exploring Sustainability Science A Southern African Perspective, eds M. Burns \& A. Weaver, African Sun Media, pp. 39-57, 2008.

[21] Chu, D., Strand, R. \& Fjelland, R., Theories of complexity. Complexity, 8(3), pp. 19-30, 2003.

http://dx.doi.org/10.1002/cplx.10059

[22] Shove, E., Beyond the ABC: climate change policy and theories of social change. Environment and Planning A, 42, pp. 1273-1285, 2010.

http://dx.doi.org/10.1068/a42282

[23] Wills, A., SA Copenhagen Accord pledge, 2010.

[24] Morris, M. \& Martin, L., Political Economy of Climate-relevant Change Policies: the Case of Renewable Energy in South Africa, 2015.

[25] Meadows, D., Places to intervene in a system. Whole Earth, Winter, pp. 78-84, 1997.

[26] Emison, A.G., The potential for unconventional progress: Complex adaptive systems and environmental quality policy. Duke Environmental Law and Policy Reform, 7, pp. 167-192, 1996.

[27] Baker, L., Burton, J., Godinho, C. \& Trollip, H., The political economy of decarbonisation: Exploring the dynamics of South Africa's electricity sector, 2015.

[28] Chandrashekeran, S., Morgan, B., Coetzee, K. \& Baker, L., From Statements of Intent to Institutionalised Practice: What Makes Climate Change Policies Stick? 2015.

[29] Death, C., The green economy in south africa: global discourses and local politics. Politikon, 41(1), pp. 1-22, 2014.

http://dx.doi.org/10.1080/02589346.2014.885668

[30] Geyer, R. \& Cairney, P., Introduction. In Handbook on Complexity and Public Policy, eds R. Geyer \& P. Cairney, Edward Elgar Publishing, pp. 1-19, 2015. http://dx.doi.org/10.4337/9781782549529

[31] Dombkins, D., Realizing complex policy: using a systems-of-systems approach to develop and implement policy. Journal of Policy and Complex Systems, 1(1), 2014. http://dx.doi.org/10.18278/jpcs.1.1.2

[32] Little, A., Complexity and real politics. In Handbook on Complexity and Public Policy, eds R. Geyer \& P. Cairney, Edward Elgar Publishing, pp. 32-47, 2015. http://dx.doi.org/10.4337/9781782549529.00009

[33] Room, G., Complexity, power and policy. In Handbook on Complexity and Public Policy, eds. R. Geyer \& P. Cairney, Edward Elgar Publishing, pp. 19-31, 2015. http://dx.doi.org/10.4337/9781782549529.00008 